\title{
Serologic Response of Spf Chickens to Live Vaccines and other Strains of Mycoplasma gallisepticum
}

- Author(s)
Nascimento ER do ${ }^{1 *}$
Polo P de $\mathrm{A}^{1}$
Pereira VL de $\mathrm{A}^{1}$
Barreto $\mathrm{ML}^{2}$
Nascimento M da GF do
Zuanaze MAF
Corrêa ARA
Silva R de CF

1 Departamento de Saúde Coletiva Veteri-
nária e Saúde Pública, Faculdade de Veteri-
nária, Universidade Federal Fluminense (UFF),
Niterói, RJ, Brazil.
2 Graduate student, Núcleo de Animais de
Laboratório, UFF. Niterói, RJ, Brazil.
3 Embrapa Agroindústria de Alimentos. Rio de
Janeiro, RJ, Brazil.
4 Laboratório Biovet S/A. Vargem Grande
Paulista, SP, Brazil.
5 PESAGRO-RIO. Niterói, RJ, Brazil.

\section{Mail Address}

Elmiro Rosendo do Nascimento
Universidade Federal Fluminense
Faculdade de Veterinária
Rua Vital Brazil Filho, 64, Vital Brazil
24.230-340. Niterói, RJ, Brazil
Telephone: (+55) 2126299536
E-mail: elmiro@vm.uff.br

Keywords

Mycoplasma, poultry, serology, vaccination.

\section{- Acknowledgements}

This study was supported by grants from Conselho Nacional de Desenvolvimento Científico e Tecnológico (CNPq) and scholarship from Coordenação de Aperfeiçoamento de Pessoal de Nível Superior (CAPES), Brazil.

\section{ABSTRACT}

False positive serologic reactions and difficulties in the diagnosis of Mycoplasma gallisepticum (MG) in chickens have increased lately as a result of infection by low virulent MG strains and the use of live MG vaccines in poultry. The objective of this study was to evaluate the serologic responses of SPF chickens exposed to the three commercially available live MG vaccines, and one low virulent MG strain (MG-70), contributing to the diagnosis and monitoring of MG infection in birds. Six groups of SPF chickens were used. The control group was not infected nor challenged; one group was infected with the low virulent strain MG-70 (MG-70); three groups were immunized and named after the MG vaccine used, i.e., MG-6/85, MG-ts11, and MG-F; and finally one group was infected with the virulent MG standard strain, MG-R. Random Amplification of Polymorphic DNA (RAPD-PCR) was used to compare the strains to each other, to the standard MG-A5969, and to MG-R. All strains were found to be genetically distinguishable from each other. Birds in the control group showed negative results throughout the experiment and showed no cross-reaction with $M$. synoviae in any serologic test. ELISA tests at 21 days post first exposure (P1E) and seven days after the second exposure (P2E), evidenced that 25\% of the MG-70 birds were positive, whereas vaccine groups yielded higher positivity rate, i.e., $57 \%, 43 \%$ and $29 \%$ for MG-6/85, MG-ts 11 and MG-F, respectively. Serum plate agglutination (SPA) evidenced the first positive results at 35 days P1E on birds in the MG-F group at the rate of $100 \%$; followed by $40 \%$ of birds in the MG-70 group at 63 days P1E. Chickens in MG-ts11 and MG 6/85 groups had identical behavior and yielded $100 \%$ positive SPA at 77 days P1E. In regard to hemagglutination inhibition $(\mathrm{HI}), 14 \%$ of the birds in MG-F and MG-ts11 reacted at 42 days P1E, while MG-70 and MG-6/85 groups yielded positive results only after challenge; MG-70 birds reacted at 56 days P1E at the rate of $17 \%$ against 63 days P1E for $100 \%$ of MG-6/85 birds. The time lag for positive serologic response was monitored on a weekly basis and was statistically different among groups $(p<0.05)$ by Analysis of Variance (ANOVA). No clinical signs or gross lesions were seen in the control, vaccinated or MG-70 infected birds. Tracheitis and airsaculitis were observed in birds in the MG-R group. MG was isolated from all studied groups.

\section{INTRODUCTION}

Mycoplasma gallisepticum (MG) is the etiologic agent of Chronic Respiratory Disease (CRD) in chickens and Infectious Sinusitis in turkeys. Avian mycoplasmosis affects breeder flocks, feed and egg production efficiency, and increase mortality and carcass condemnation. Such economic losses justify the acquisition of MG-free birds as a means to 
Nascimento ER do, Polo P de A,

Pereira VL de A, Barreto ML,

Nascimento $M$ da GF do, Zuanaze

MAF, Corrêa ARA, Silva R de CF

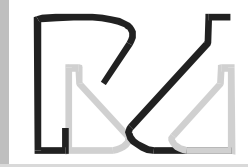

Serologic Response of Spf Chickens to Live Vaccines and other Strains of Mycoplasma gallisepticum

reduce or eliminate $M G$ infection in the poultry industry, according to control and eradication programs (Fiorentin, et al., 1992; Ley \& Yoder, 1997; Nascimento, 2000). Comparative studies have supported the use of live vaccines in the control of MG infection in birds (Abdel-Motelib \& Kleven, 1993; Cummings \& Kleven, 1986; Evans \& Hafez, 1992; Levisohn, 1984; Ley et al., 1997). In Brazil and in other countries, the live vaccines MG6/85, MG-ts 11 and MG-F are used to control mycoplasmosis in layer flocks. In breeders, the government programs restrict the use of $M G$ live vaccines (Brasil, 1994; Brasil, 2001; USA, 2002).

The serologic tests recommended by governmental poultry health programs for monitoring of mycoplasmosis are serum plate agglutination (SPA), hemagglutination inhibition (HI) and ELISA, because they are inexpensive and easy to be performed (Brasil, 1994; Brasil, 2001; USA, 2002). However, crossreactions among mycoplasma species and non-specific reactions have caused a serious problem of misdiagnosis in serologic surveys (Levisohn, 1984; Mendonça et al., 2000). The appearance of low virulent MG strains and the use of antimicrobial drugs that accumulate in the respiratory tract have been responsible for false negative results, and have thus limited the usefulness of serologic tests for the monitoring of poultry diseases. MG vaccines have also been reported as a factor interfering with mycoplasma diagnosis, and subsequently there has been the need of confirmation by PCR and/or isolation (Mendonça et al., 2000; Nascimento et al. 1991; Nascimento et al., 1994). Consequently, it is necessary to presume the expected serologic response in birds that have been vaccinated or exposed to low virulent strains (Abd-elMotelib \& Kleven, 1993; Evans \& Hafez, 1992; Ley et al., 1997).

This study evaluated the serologic response of SPF chickens exposed to a low virulent MG strain and to the live MG vaccines commercially available in Brazil. Response evaluation intends to contribute to the diagnosis and monitoring of $M G$ infection in birds. Additionally, RAPD-PCR analysis was used to differentiate between the MG strains.

\section{MATERIAL AND METHODS}

Experimental design. There were six groups of SPF chickens (BIOVET - SP/Brazil) kept in isolation units and exposed to different MG strains: control (non immunized and not challenged); MG-70, immunized with a low virulence field strain; MG-R (ATCC 19610), which was not immunized, but challenged; and three groups immunized using commercial live vaccines, i.e., MG-6/85 (Akzo Nobel Ltda-Intervet, São Paulo, SP, Brazil), MG-ts11 (Merial Saúde Animal Ltda, Campinas, SP, Brazil) and MG-F (Schering Plough Coopers Brasil Ltda, São Paulo, SP, Brazil). MG strains had shown diverse banding patterns by RAPD-PCR (Fan, Kleven \& Jackwood, 1995). All groups consisted of 30 birds at 21 days of age ( $1^{\text {st }}$ exposure), except MG-R. This group was established with half the birds and when they were 70 days old (49 days after the beginning of the trial). Exposures were performed at 21 and 35 days old. Vaccines were reconstituted according to the protocol suggested by each manufacturer. The strain MG-70 was used at the titer of $10^{6.79}$ Color Change Unit (CCU)/ $\mathrm{mL}$. MG vaccines, the low virulence MG-70 and MG-R strains were administered using eye drops $(50 \mathrm{~mL}$ per bird). The control group was neither exposed nor challenged. In the other groups, challenge was performed twice with chicken embryo-activated MG$R$ at 70 and 84 days of age. The first challenge was done at 49 days post first exposure (P1E) and it was used a titer of $10^{1.5}$, whereas the second challenge was done at 63 days P1E and titer of $10^{4.5}$. Serologic response by SPA, ELISA and HI was monitored weekly, from the day of exposure (21 days old, zero P1E) until 84 days P1E (105 days old). Necropsies were performed at $14,35,63$ and 77 days P1E. Samples for histological examination and recovery of MG strains were collected as shown in Table 1.

RAPD-PCR. Fresh cultures of MG-70, MG-6/85, MGts11, MG-F, MG-A5969 and MG-R were prepared using Frey medium (Frey, Hanson \& Anderson, 1968) and freeze-stocks in glycerol were separated. Genomic DNA from the MG cultures was extracted by the method of phenol-chloroform with Proteinase K; cellular lysis with 10\% SDS, ethanol precipitation and resuspension in $100 \mathrm{~mL}$ TE Buffer (Sambrook, Fritsch \& Maniatis, 1989). DNA amplification was carried out with a thermocycler PTC-100 (Peltier Effect Cycling, MJ Research, Inc), according to previously reported conditions, except that only one primer was used (200 pmol, M16SPCR 5'C - AGG GAG GAG TAG GGA AT $3^{\prime} \mathrm{OH}$ - Bio-synthesis - lot (228-26). It was used three cycles at $94^{\circ} \mathrm{C}$ for 15 seconds (denaturation), $28^{\circ} \mathrm{C}$ for two minutes (annealing) and at $74^{\circ} \mathrm{C}$ for three minutes (extension), followed by 35 cycles at $94^{\circ} \mathrm{C}$ for 15 seconds, $45^{\circ} \mathrm{C}$ for two minutes and at $74^{\circ} \mathrm{C}$ for three minutes (Fan, Kleven \& Jackwood, 1995). Amplicons were visualized after agarose gel electrophoresis and staining with ethidium bromide under ultraviolet light. 
Nascimento ER do, Polo P de A,

Pereira VL de A, Barreto ML, Nascimento M da GF do, Zuanaze MAF, Corrêa ARA, Silva R de CF
Serologic Response of Spf Chickens to Live Vaccines and other Strains of Mycoplasma gallisepticum

\begin{tabular}{|c|c|c|c|}
\hline Days post- $1^{\text {st }}$ exposure & Age(days) & Procedure & Sampling \\
\hline- & 0 & Chickens housed in isolators & - - \\
\hline 0 & 21 & $1^{\text {st immunization }}$ & Serum \\
\hline 7 & 28 & - & Serum \\
\hline \multirow[t]{2}{*}{14} & 35 & Necropsy & \\
\hline & & $2^{\text {nd }}$ immunization & Serum and tissue \\
\hline 21 & 42 & - - & Serum \\
\hline 28 & 49 & - - & Serum \\
\hline 35 & 56 & Necropsy & Serum and tissue \\
\hline 42 & 63 & -- & Serum \\
\hline \multirow[t]{2}{*}{49} & 70 & Establishment of challenged group & \\
\hline & & $1^{\text {st }}$ challenge & Serum \\
\hline 56 & 77 & - & Serum \\
\hline \multirow[t]{2}{*}{63} & 84 & Necropsy & \\
\hline & & $2^{\text {nd }}$ challenge & Serum and tissue \\
\hline 70 & 91 & - & Serum \\
\hline 77 & 98 & Necropsy & Serum and tissue \\
\hline
\end{tabular}

Serology. Blood samples were collected weekly from 10 birds of each group to assess antibody levels using SPA, ELISA and HI. Samples were collected before the $1 \mathrm{E}$ and continued throughout the experiment. The obtained sera were immediately tested by SPA against MG and $M$. synoviae (MS) antigens, according to the manufacturer instructions (Biovet, SP, Brazil). Undiluted sera positive by SPA were considered suspicious and were thus further diluted and tested again. The serum was considered positive if positivity was seen at 1:10 dilution or higher, according to the guidelines from the National Poultry Health Program (Programa Nacional de Sanidade Avícola, PNSA; Brasil, 1994). ELISA was performed using M. gallisepticum Antibody Test Kit (IDEXX, SP, Brazil), according to the provided protocol. ELISA results were considered positive when positivity was detected at titers equal or higher than 1076 (S/P coefficient $>0.5$ ). $\mathrm{HI}$ antigens for $\mathrm{MG}$ and $\mathrm{MS}$ were prepared in the laboratory and considered positive when tested sera reacted to titers $\geq 1: 40$ (Whitford, Rosenbush \& Lauerman, 1993).

Clinical samples and MG isolation. Five chickens from each group were necropsied at 14, 35, 63 and 77 days $\mathrm{P} 1 \mathrm{E}$ and gross lesions on organs affected by mycoplasmosis were recorded. Fragments of trachea and air sacs were placed into 10\% formalin for histological evaluation. Swabs from trachea and air sacs from each necropsied chicken were frozen and stored in $2 \mathrm{~mL}$ of Frey Modified Broth diluted to 1:2 with glycerol (Frey, Hanson \& Anderson, 1968; Nascimento, 2000). Samples were also cultured on Frey Modified Agar and Frey Modified Broth, and then incubated at $37^{\circ} \mathrm{C}$ for up to 21 days, with daily observations (Brasil, 1994). Samples were considered negative and discarded when no Mycoplasma colonies were visualized. Colonies on Frey Agar were typed by Direct Immunofluorescence using an Epifluorescence Microscope (INALH, OSSIPAN - RJ - Brazil) and compared to MG-positive controls at 10 to $40 x$ magnification. Positive colonies showed intense green fluorescence, whereas negative colonies yielded no or slight fluorescence (Kleven \& Levisohn, 1995; Whitford, Rosenbush \& Lauerman, 1993).

Statistical Analysis. Positivity was compared among groups using $100 \%$ of positivity or at the end of the trial (if one group had not reached 100\%). Differences among positive proportions were evaluated by group and by test used using Chi Square $\left(X^{2}\right)$, according to a follow-up period of seven days. The time lag for the first appearance of serologic reaction in each group by test, either partially or completely $(100 \%$ of birds) was done using Analysis of Variance (ANOVA) at $95 \%$ confidence interval $(\mathrm{Cl})$ in a follow-up period of seven days, as previously described (Martin, Meek \& Willeberg, 1987).

\section{RESULTS}

All vaccine strains used in this study were considered to be genetically distinguishable from each other and also from MG-70, the standards MGA5969 and MG-R by RAPD-PCR (Figure 1). MG was recovered during and at the end of the trial.

Control birds were serologically negative for MG and MS, while birds in the other groups were negative for MS in all serologic tests throughout the trial. Chickens inoculated with MG-70 and vaccine strains were MG-negative by SPA up to 28 days P1E (49 days old). However, at 35 P1E (56 days old), 100\% of the birds in the group MG-F were reactive by SPA either using undiluted or diluted (1:10) sera. SPA reaction only 
Nascimento ER do, Polo P de A,

Pereira VL de A, Barreto $M L$,

Nascimento M da GF do, Zuanaze

MAF, Corrêa ARA, Silva R de CF

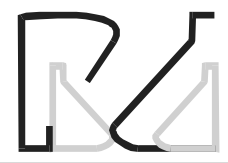

Serologic Response of Spf Chickens to Live Vaccines and other Strains of Mycoplasma gallisepticum occurred after challenge in the groups inoculated with MG-70 and the other vaccines. SPA positivity was seen in $40 \%$ of the MG-70 birds only at 63 days P1E (84 days old). Nevertheless, $80 \%$ of the birds showed positive results at 42 days P1E ( 63 days old) if undiluted sera were used, even before challenge. Chickens exposed to MG-ts11 and MG 6/85 showed similar SPA results; they produced suspicious reactions with undiluted sera only at 49 days P1E at the rate of $20 \%$, and positive results were seen in $100 \%$ of the birds only at 77 days P1E (98 days old). The MG-R group was $100 \%$ suspicious at 7 days post first challenge (P1C), i.e., 77 days old, and $63 \%$ of the birds were SPA-positive at 14 days P1C (84 days old) (Table 2 ).

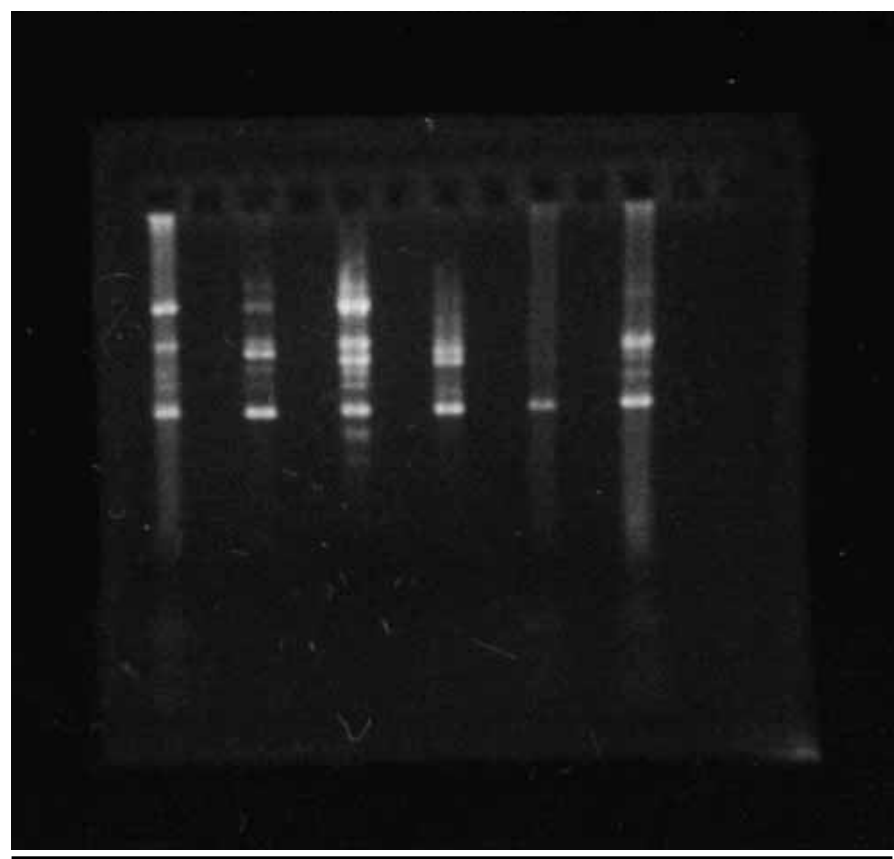

Figure 1 - RAPD-PCR patterns of Mycoplasma gallisepticum strains. From left to right: MG-A5969, MG-F, MG-6/85, MGTS11, MG-70 and MG-R.

Positive ELISA titers were seen at 21 days P1E (42 days old) in birds in the groups MG-70, MG-F, MGts 11 and MG-6/85 (25\%, 29\%, 43\% and 57\%, respectively). In MG-R group, $100 \%$ of the birds were positive at 7 days P1C. Vaccine groups became 100\% positive at 35 days P1E (56 days old), whereas MG-70 birds were $100 \%$ positive at 42 days P1E (63 days old) (Table 2).

MG-F and MG-ts11 groups had positive $\mathrm{HI}$ results $(14 \%)$ at 42 days P1E (63 days old), that is, before being challenged. On the other hand, positive results were seen only after the challenge in MG-70 (17\%) and MG$6 / 85(100 \%)$, i.e., 56 days P1E (77 days old) and 63 days P1E (84 days old), respectively. Chickens in MG-R group were SPA positive (83\%) as early as seven days P1C (Table 2).

The positivity proportions in exposed groups (MG70, MG-6/85, MG-ts11 and MG-F) were statistically different $(p<0.05)$ by $X^{2}$ in the serologic procedures (SPA with undiluted sera, SPA with serum diluted to 1:10, ELISA, and $\mathrm{HI}$ ).

The time lag for serologic response was statistically different between groups $(p<0.05)$ by ANOVA and depended on the serologic method, either for the onset of reaction or for time lag until $100 \%$ of birds became positive (Table 2 ). In concern to the time lag for the reactivity onset, MG-70, MG-6/85 and MG-ts11 were significantly different from $M G-R(p<0.05)$. On the other hand, when $100 \%$ positivity was considered, MG-R was significantly different $(p<0.05)$ from the other groups (Table 2). Regardless of treatment, serologic reactivity was first detected by ELISA, followed by SPA with undiluted sera, SPA with 1:10 diluted sera, and $\mathrm{HI}$ (Table 2$)$. MG-R reactivity was detected faster $(100 \%$ positive), regardless of methodology (Table 2 ).

All strains provided protection, although at different degrees, as measured by the increase of seroconversion. Protection may also be inferred from the absence of disease signs and gross lesions in birds in MG-70 and the three vaccine groups. No disease signs or gross lesions were seen in chickens from the exposed groups. Tracheitis and airsaculitis were observed only in MG-R.

\section{DISCUSSION}

The MG strains evaluated were genetically distinguishable by RAPD-PCR. This corroborates the hypothesis of this study, because it evidences that the low virulence strain MG-70 was not a recovery of a MG vaccine strain. Except for MG-70, these results corroborate previous reports (Fan, Kleven \& Jackwood, 1995; Ley \& Yoder, 1997).

The absence of cross-reaction with MS throughout the trial in all groups might be because there were no environmental factors interfering on the experimental conditions, as noticed earlier (Nascimento et al., 1993; Nascimento, 2000).

In a previous study, SPA results were scored from 0 to 4 (Abd-El-Motelib \& Kleven, 1993). Reactivity was present in MG-ts-11 within about 28 days post-vaccination and decreased in the end of the trial (84 days), while MG-6/85 only elicited SPA reaction at about 42 days, which has also decreased thereafter. 
Nascimento ER do, PoloP de A,

Pereira VL de A, Barreto ML,

Nascimento M da GF do, Zuanaze

MAF, Corrêa ARA, Silva R de CF
Serologic Response of Spf Chickens to Live Vaccines and other Strains of Mycoplasma gallisepticum

\begin{tabular}{|c|c|c|c|c|c|c|c|c|c|c|c|c|c|c|c|}
\hline & \multirow[b]{2}{*}{ Groups } & \multirow[b]{2}{*}{ Tests } & & \multicolumn{12}{|c|}{ Days P1E } \\
\hline & & & \multirow[b]{2}{*}{ und } & $\overline{0^{\mathrm{E}}}$ & 7 & $14^{\mathrm{E}}$ & 21 & 28 & 35 & 42 & $49^{c}$ & 56 & $63^{c}$ & 70 & 77 \\
\hline & MG-70 & SPA & & 0 & 0 & 0 & 0 & 0 & 0 & $80^{a}$ & 80 & $100^{x}$ & 100 & 100 & 100 \\
\hline & & & dil & 0 & 0 & 0 & 0 & 0 & 0 & 0 & 0 & 0 & $40^{a}$ & $100^{x}$ & 100 \\
\hline & & ELISA & & 0 & 0 & 0 & $25^{a}$ & 38 & 88 & $100^{x}$ & 100 & 100 & 100 & 100 & 100 \\
\hline & & $\mathrm{HI}$ & & 0 & 0 & 0 & 0 & 0 & 0 & 0 & 0 & $17^{a}$ & 67 & 67 & NT \\
\hline & MG-6/85 & SPA & und & 0 & 0 & 0 & 0 & 0 & 0 & 0 & $20^{a}$ & 20 & $100^{x}$ & 100 & 100 \\
\hline 은 & & & dil & 0 & 0 & 0 & 0 & 0 & 0 & 0 & 0 & 0 & 0 & 0 & $100^{a, x}$ \\
\hline б̆ & & ELISA & & 0 & 0 & 0 & $57^{a}$ & 86 & $100^{x}$ & 100 & 100 & 100 & 100 & 100 & 100 \\
\hline ฉे & & $\mathrm{HI}$ & & 0 & 0 & 0 & 0 & 0 & 0 & 0 & 0 & 0 & $100^{a, x}$ & 100 & NT \\
\hline$\widehat{0}$ & MG-ts 11 & SPA & und & 0 & 0 & 0 & 0 & 0 & 0 & 0 & $20^{a}$ & 20 & $100^{x}$ & 100 & 100 \\
\hline e & & & dil & 0 & 0 & 0 & 0 & 0 & 0 & 0 & 0 & 0 & 0 & 0 & $100^{a, x}$ \\
\hline ñ & & ELISA & & 0 & 0 & 0 & $43^{a}$ & 43 & $100^{x}$ & 100 & 100 & 100 & 100 & 100 & 100 \\
\hline ق & & $\mathrm{HI}$ & & 0 & 0 & 0 & 0 & 0 & 0 & $14^{\mathrm{a}}$ & 33 & 33 & 88 & NT & NT \\
\hline$\stackrel{\Perp}{\geq}$ & $M G-F$ & SPA & und & 0 & 0 & 0 & 0 & 0 & $100^{a b, x}$ & 100 & 100 & 100 & 100 & 100 & 100 \\
\hline$\frac{\bar{n}}{n}$ & & & dil & 0 & 0 & 0 & 0 & 0 & $100^{a b, x}$ & 100 & 100 & 100 & 100 & 100 & 100 \\
\hline ¿ & & ELISA & & 0 & 0 & 0 & $29^{a b}$ & 71 & $100^{x}$ & 100 & 100 & 100 & 100 & 100 & 100 \\
\hline & & $\mathrm{HI}$ & & 0 & 0 & 0 & 0 & 0 & 0 & $14^{a b}$ & 14 & 43 & $100^{x}$ & 100 & NT \\
\hline & MG-R (Challenge) & SPA & und & 0 & 0 & 0 & 0 & 0 & 0 & 0 & 0 & $100^{b, y}$ & 100 & 100 & 100 \\
\hline & & & dil & 0 & 0 & 0 & 0 & 0 & 0 & 0 & 0 & 0 & $63^{b}$ & $100^{y}$ & 100 \\
\hline & & ELISA & & 0 & 0 & 0 & 0 & 0 & 0 & 0 & 0 & $100^{b, y}$ & 100 & 100 & 100 \\
\hline & & $\mathrm{HI}$ & & 0 & 0 & 0 & 0 & 0 & 0 & 0 & 0 & $83^{b}$ & 83 & $100^{y}$ & NT \\
\hline
\end{tabular}

$\mathrm{P} 1 \mathrm{E}=$ post-first exposure; $\mathrm{P} 1 \mathrm{C}=$ post first challenge; und $=$ SPA with undiluted sera; dil = SPA with $1: 10$ diluted sera; $\mathrm{C}=\mathrm{Challenge}$; NT= not tested. ANOVA, time lag to reaction onset, different smaller letters $(a, b, c)$ indicate different results; time lag to $100 \%$ positive birds, different smaller letters $(x, y)$ indicate different results.

In the present study, MG-ts11 and MG-6/85 results were similar, eliciting $20 \%$ SPA reaction only at 49 days P1E with undiluted sera. These differences might have occurred because of spa scoring and different chicken type used in the above mentioned report. On the other hand, MG-F was reported to be the first to elicit SPA positive reaction at about 28 days post-vaccination by Abd-El-Motelib \& Kleven (1993), which is similar to the result reported herein (35 days P1E). Ley at al. (1997) detected $60 \%$ SPA positive pullets 42 days after vaccination for MG-ts 11 , but no positivity after vaccination using MG-6/85; in this latter trial the birds were also negative for MG by ELISA and $\mathrm{HI}$. These authors used eye-eyelid drop and spray for MG-ts11 and MG-6/ 85 as inoculation routes, respectively, and used turkeys as models, which may have accounted for the differences.

In ELISA, positive sera were detected in all groups before the challenge at 21 days P1E. On the other hand, a previous work has shown no reactivity to MG-6/85 in exposed birds and absence or weak serologic response to MG-ts11, respectively (Abd-el-Motelib \& Kleven, 1993; Ley at al., 1997). These differences might have been accounted for by the use of different ELISA kits, types of bird, and routes of exposure.

$\mathrm{HI}$ results for MG-ts 11 and MG-F are in accordance with others, but not MG-6/85 results (Abd-el-Motelib \& Kleven, 1993; Levisohn, 1984). These contrasting results may be justified by the different experimental designs, such as processing/preparation of $\mathrm{HI}$ antigen and red blood cells (Ley at al., 1997).
MG-ts 11 and MG-6/85 strains elicited weak or no vaccination reactions. These results are in agreement with other studies (Abd-el-Motelib \& Kleven, 1993; Evans \& Hafez, 1992; Ley at al., 1997). MG-F strain, as well as MG-70, MG-6/85 and MG-ts11, were not able to elicit any respiratory symptom on the inoculated chickens. Previously, a mild respiratory reaction has been reported in the group MG-F between five and fifteen days post vaccination (Abd-el-Motelib \& Kleven, 1993). In the present study, it was also not detected any gross lesions of airsaculitis and tracheitis in any of the groups, except for MG-R, which is in agreement with previous reports (Abd-el-Motelib \& Kleven, 1993; Evans \& Hafez, 1992; Ley at al., 1997).

These results contribute to the diagnosis of MG infection in breeding flocks, mainly when vaccine and/ or low virulent strains are involved. Besides, SPA reaction with undiluted serum should be considered a suspicious result, rather than a negative one (USA, 2002; Brasil, 2001).

\section{REFERENCES}

Abd-el-Motelib TY, Kleven SH. A comparative study of Mycoplasma gallisepticum vaccines in young chickens. Avian Diseases 1993; 37:981-7.

Brasil. Portaria Ministerial n 193, de 19 de setembro de 1994. Institui o Programa Nacional de Sanidade Avícola do Ministério da Agricultura e Abastecimento (MAA). Diário Oficial da República Federativa do Brasil, Brasília/DF; 1994. 
Nascimento ER do, Polo P de A,

Pereira VL de A, Barreto $M L$,

Nascimento M da GF do, Zuanaze

MAF, Corrêa ARA, Silva R de CF

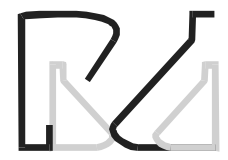

Serologic Response of Spf Chickens to Live Vaccines and other Strains of Mycoplasma gallisepticum
Brasil. Instrução normativa $n^{\circ} 44$, de 23 de agosto de 2001. Aprova as normas técnicas para o controle e certificação de núcleos e estabelecimento avícola para a Micoplasmose Aviária do Ministério da Agricultura, Pecuária e Abastecimento (MAPA). Diário Oficial da República Federativa do Brasil, Brasília/DF, n.163, 24 de agosto; 2001. Seção 1.

Cummings TS, Kleven SH. Evaluation of protection against Mycoplasma gallisepticum infection in chickens vaccinated with the F strain of Mycoplasma gallisepticum. Avian Diseases 1986; 30:169-171.

Evans RD, Hafez YS. Evaluation of a Mycoplasma gallisepticumstrain exhibiting reduced virulence for prevention and control of poultry Mycoplasmosis. Avian Diseases 1992; 36:197-201.

Fan HH, Kleven SH, Jackwood, MW. Application of polymerase chain reaction with arbitrary primers to strains identification of Mycoplasma gallisepticum. Avian Diseases 1995; 39:729-735.

Fiorentin L, Nascimento ER, Balen L, Nascimento MGF, Ávila V, Schmidt GS. Erradicação de micoplasmas em plantéis de galinhas de linhas puras. In: Conferência APINCO de Ciência e Tecnologia Avícolas; 1992; Santos, Brasil. Campinas: FACTA; 1992. p.205.

Frey ML, Hanson RP, Anderson DP. A medium for the isolation of avian mycoplasmas. America Journal of Veterinary Research 1968; 29:2163-2171.

Kleven SH, Levisohn S. Mycoplasma infection of poultry. In: Tully JG, Razin S, editors. Molecular and diagnostic procedures in mycoplasmology. New York: Academic Press 1995; 2:283-292.

Levisohn S. Early stages in the interaction between Mycoplasma gallisepticum and the chick trachea as related to pathogenicity and immunogenicity. Israel Journal Medical Science 1984; 20:982-4.

Ley DH, Mc Laren JM, Milles AM, Barnes HJ, Miller SH, Fraz G. Transmissibility of live Mycoplasma gallisepticum vaccine strains ts-11 and 6/85 from vaccinated layers pullets to sentinel poultry. Avian. Diseases 1997; 41:187-194.

Ley DH, Yoder Jr. HW. Mycoplasma gallisepticum infections. In: Calnek BW, Barnes HJ, Beard CW, McDougald LR, Saif YM. Diseases of poultry. $10^{\text {th }}$ ed. Ames: Iowa State University Press; 1997. p.194207.

Martin SW, Meek AH, Willeberg P. Veterinary epidemiology principles and methods. Ames: lowa State University Press; 1987. p.343.

Mendonça GA, Nascimento ER, Lignon GB, Nascimento MGF, Polo PA. Utilização da Reação em Cadeia de Polimerase (PCR) na detecção de Mycoplasma gallisepticum (MG) em galinhas poedeiras com infecção natural e vacinadas com MG. In: Congresso de Produção e Consumo de Ovos 1. 2000; São Paulo, Brasil. São Paulo (SP): APA; 2000. p.170-171.

Nascimento ER, Yamamoto R, Herrick KR, Tait RC. Polymerase chain reaction for detection of Mycoplasma gallisepticum. Avian Diseases $1991 ; 35: 62-69$.
Nascimento ER, Yamamoto R, Khan MI. Mycoplasma gallisepticum $F$-vaccine strain-specific polymerase chain reaction. Avian Diseases 1993; 37:203-211.

Nascimento ER, Yamamoto R, DaMassa AJ, Ortmayer HB, Nascimento MGF. PCR versus isolamento e sorologia no diagnóstico da infecção por Mycoplasma gallisepticum em galinhas e perus. In: Conferência APINCO 1994 de Ciência e Tecnologia Avícolas; 1994; Santos, Brasil. Campinas (SP): FACTA; 1994. p.89-90.

Nascimento ER. Micoplasmoses. In: Berchieri Jr. A., Macari M, editores. Doenças das aves. Campinas (SP): FACTA; 2000. p.217224.

Sambrook KJ, Fritsch EF, Maniatis T, editors. Molecular clonning: a laboratory manual. $2^{\text {nd }}$ ed. New York (NY): Cold Spring Harbour Laboratory 1989; 3:3-15.

USA. National Poultry Improvement Plan And Auxiliary Provisions. Department of Agriculture. Animal And Plant Health Inspection Service. [accessed ago.8, 2002]. Available from: http:// www.aphis.usda.gov/vs/npip/ .

Whitford WH, Rosenbush RF, Lauerman LH, editors. Mycoplasmosis in animals: laboratory diagnosis. Ames: Iowa State University; 1993. p.173. 